\title{
The Influence of Childhood Training on the Adulthood Rejection of Discrimination in Go Set a Watchman
}

\author{
Faeze Rezazade*1, a ${ }^{*}$ Esmaeil Zohdi ${ }^{2, b}$ \\ ${ }^{* 1,2}$ Department of English Literature, Faculty of Humanities, Vali-e-Asr University, \\ Rafsanjan, Kerman, Iran
}

afaezerezazade.1991@gmail.com, besmaeil_zohdi@yahoo.com

\begin{abstract}
Keywords: Social discrimination, Children training, Go Set a Watchman, Harper Lee.
\end{abstract}
\begin{abstract}
Racial prejudice, injustice, and discrimination against people of colored skin, especially African Americans, has become a global issue since the twenty century. Blacks are deprived of their rights regardless of their human natures and are disenfranchised from White's societies due to their skin color which has put them as inferior and clownish creatures in White's point of view. Although many anti-racist effort and speeches has done to solve racist issues and eliminate racism and its circumstances, still racism is alive and Blacks are suffering from it. Although, many White individuals accept themselves as anti-racist characters that color of skin does not matter to them, they still show prejudice and discrimination towards Blacks and cannot consider them as equal as themselves. A reason to such Whites' thought and behavior is that they have faced this issue since their childhood and therefore they cannot change it because this attitude is entangled with their personality and is deeply ingrained in them. Thus, a way to stop and eliminate discrimination, prejudice, and injustice is to train children, the next generation, as anti-racist and color-blind characters. In this regard, it has been tried to investigate the role of children training in the elimination of social and racial discrimination in Harper Lee's Go Set a Watchman (2015), which is sequel novel to her masterpiece To Kill a Mockingbird (1960). Moreover, Jean Piaget's theory of Children's Cognitive Development has been used for a better understanding of this investigation.
\end{abstract}

\section{Introduction}

Since prejudice, discrimination, and racial injustice towards Blacks has caused many problems for this kind of human race and has taken away their rights as human beings racism and racist practices has become a global issue. Racist activities and speeches and also violence, including beatings and killings, has made many anti-racist activators and writers to defend Blacks' rights and obliterate racism. Although anti-racist activities, committees, and institutions has reduced racism and its bad effects around the world, still racism is alive, especially in America, and the world is still a witness for such bad behaviors and treatments towards people of different skin colors, especially Blacks. However, many white individuals accept themselves as anti-racist characters that color of skin does not matter to them, they still show prejudice and discrimination towards Blacks and cannot consider them as equal as themselves. Whites view Blacks as a kind of danger for themselves who are inferior and uncivilized that are not deserved to coexist with them. A reason to such Whites' thought and behavior is that they have faced this issue since their childhood and therefore they cannot change it because this attitude is entangled with their personality and is deeply ingrained in them. Thus, a way to stop and eliminate discrimination, prejudice, and injustice is to train children, the next generation, as anti-racist and color-blind characters.

Young children, however unaware of racism, are curious about racial, physical and cultural characteristics. According to a prevailing majority culture ideology "children are "color-blind," i.e., they are unaware of race and racism" [1, p. 2]. In addition, it can be argued that in order to have non-prejudiced adults in future, children should not face racist attitudes as stereotypes around them and should learn to avoid discrimination and prejudice. Therefore, racism and racist attitudes should be avoided and denied in childhood since children are facing with cultural and racial differences during their childhood and therefore are aware of them. 
Researchers, like Devine, have long posited that non-conscious or implicit racial prejudice develops via exposure to prejudicial socializing agents starting in childhood [2]. Since children are in contact with their parents more than anybody else, therefore, there is a relationship between parents' racial attitudes and their children's implicit prejudice. Children will "naturally" grow up to be non-racist adults only when they live in a non-racist society. Until then, adults must guide children's anti-racist development. Ann Beuf points out,

On the other hand, parental training which contradicts ["color-blind" ideologies] can play a vital role in establishing positive racial attitudes in children. ... Our data with the children of activists suggests that a home in which the positive value of [one's group] is stressed will produce children who feel positive about their group [3, p. 119].

\section{Jean Piaget's Theory of Children Cognitive Development}

Jean Piaget (1896) was a Swiss clinical psychologist known for his pioneering work in child development. Piaget placed great importance on the education of children because he believed that, "only education is capable of saving our societies from possible collapse, whether violent, or gradual" [4, p. 31]. According to Jean Piaget's theory of cognitive development, "children begin with intuitive concepts based on immediate experiences and gradually become capable of increasingly complex and logical thinking" [1, p. 5]. Moreover, it is obvious that racial differences exist and children face racial issues at different stages in their development. In addition, these differences only become racist when either inferior or superior value labels are placed upon them.

Piaget classifies children of three- to twelve year olds into three categories based on the development of their cognitive features and characteristics; three- to five, five- to eight, and eightto twelve year olds. In fact, Piaget believes that these ages are sensitive ages in which children are ready to be racist or anti-racist for the rest of their life.

The systematic "pre-operational" patterns of thought, as Piaget calls, is exhibited by children of three- to five year olds. In fact, children's questions at this period of age reveal how much they are aware of social and racial issues. Indeed, preschoolers pay attention to the physical and cultural characteristics of themselves and the others, at first their differences in the color of the skin then in language and dress. Moreover, many of their comments and sentences are based on their observation. While young children are excellent observers, their experience is limited. They face new experiences but use their previous explanations for describing. Piaget describes this approach as "egocentric," i.e., the child's explanations make sense from the child's point of view, but may not be accurate from an adult's point of view.

As it was mentioned before, children at this age began to distinguish between themselves and the others based on the racial differences that they face in the form of different skin colors. They try to classify people so they learn 'colors'. They learn also the social meaning of the colors when applying to a special race, for example they learn that Africans are black. Thus, inaccurate and stereotypic beliefs, caricatured images and information about racial/cultural groups are particularly harmful at this age. In addition, children learn the concept of "group" at this age and the first group that they know is family. Children learn that their physical and cultural characteristics are derived from the family which they belong. And the group that they belong to it is included from the same families with same cultural and racial characteristics. In this regard, it is family who help the child learning the racial/cultural characteristics of a specific group. Thus, any prejudice or stereotypes against a specific group will remain in the child's mind forever.

Children at the age of five- to eight-years-old are moving into a new period of cognitive development. They learn more about the cultures and their features and also the national identity and the relationships between cultures and nations. As it is argued, at this period of age children pays their attention from individual identity to group identity and their cognitive and emotional features develop at this period. This stage is defined by Piaget as "socio-centric stage" which means children's consciousness about the society and the group that they belong to and its difference from the other groups which brings them a sense of pride. 
Therefore, personal prejudice can be an integral aspect of a child's behavior if he/she grows up with wrong beliefs about other races because he/she is ready to learn at this stage. Likewise, children learn prejudice and stereotypes from the beliefs and behavior of adults who surround them. Parents, indeed, has the most effective role in children training because children imitate them, therefore, parents' behavior is a pattern for the next generation. Racial name-calling against the others can be known as a starter of racist attitudes developing in children, whether to define a special group or hurt, for example using the word "Nigger" as an impolite way of calling a Negro.

Finally, nine- to-twelve-year-olds, or pre-adolescents, deepen their understanding of the various factors defining racial/cultural identity, for example historical, political, and geographical aspects of each race and identity. They learn about their nationality, and also the nationality of their parents and their ancestors, and then decide about their own race and nationality.

Children in this age group can achieve what Piaget calls "reciprocity," i.e., understanding the interaction between individuality and group membership and the concept that all people are simultaneously humans and members of specific sub-groups, meaning that they all have both similar and different needs [5]. In fact,

The nine- to twelve-year-old period is a critical one. It is a time when racist attitudes and behavior can be consolidated; it is a time also when earlier inaccurate ideas can be challenged and changed [1, pp. 18-19].

Thus, all these three periods, from three to twelve, are important in developing the racist or anti-racist attitudes of children. In fact, children, in these periods, learn to be fair or unfair towards racial issues. Therefore, in order to combat racism, eliminate social discrimination, and increase the number of color-blind characters in the case of cultural/racial differences, childhood training can be a good solution.

\section{Discussion}

While To Kill a Mockingbird was the first novel Lee had published, it wasn't the first one which she wrote. Her first manuscript, titled Go Set a Watchman, which followed the twenty years later lives of the characters from To Kill a Mockingbird, was submitted to a publisher in 1957. When the book wasn't accepted, Lee's editor asked her to revise the story and make her main character, Scout, a child. The author worked on the story for two years and it eventually became To Kill a Mockingbird.

To Kill a Mockingbird, written by Nelle Harper Lee in 1960, can be considered as an antiracial novel which condemns racial prejudice, discrimination, and injustice. This novel has been recognized as the second moral book after Bible in America and has a widespread popularity around the world. Lee set To Kill a Mockingbird in the 1930s, the time of the Great Depression in America, to remind the readers of the socioeconomic hardship of those era and also the historic Scottsboro Trial, which Lee has fictionalized it in the story through the trial of Tom Robinson who is an innocent Negro accused of raping a white girl. She wrote this novel on the purpose of showing the immoral aspects of cultural, social, racial, and gender discriminations and indeed tried to invite people to coexist with one another despite any differences among them without prejudice and injustice. Lee also endeavored to portrait children of the novel as color-blind characters who have learned the principles of an anti-racist life from their father, Atticus Finch. Atticus, himself a colorblind and righteous character who fights against racism, teaches his children to be color-blind in the case of racism and only pay attention to humanity and good natures of people and, therefore, avoid social/racial/cultural discrimination, injustice, and prejudice. As To Kill a Mockingbird is a bildungsroman, it is about three years of Scout's and Jim's life so that Scout learns anti-racist attitudes from her six- to nine years old and Jem learns them from his nine- to twelve years old.

As the sequel novel to the story of To Kill a Mockingbird, Lee's Go Set a Watchman is also about racism and racial tension in Alabama and happens again in fictional Maycomb. It is about twenty years later incidents of To Kill a Mockingbird and deals with twenty-six years old Scout who is now a real color-blind and anti-racist person due to her childhood training and fights against 
racism and racist people, even her father Atticus who has become a racist character in Go Set a Watchman. Thus, To Kill a Mockingbird and Go Set a Watchman are good cases in point which can beautifully reveal Piaget's theory of Children's Cognitive Development. In this regard, it has been tried in this study to investigate the role of childhood training on the adulthood rejection of racial discrimination through analysis of Go Set a Watchman which is the result of Scout's childhood training.

\section{The influence of childhood training in adulthood color-blindness in Go Set a Watchman}

As it was mentioned above, Atticus Finch through lessons of moral behavior taught his children, Scout and Jem, to be color-blind in the case of racism. Moreover, having a black maid, who had the role of a real mother for Scout and Jem, put the children from their infancy in a condition of anti-racism that does not let them to differentiate between races of Whites and Blacks. In addition, Scout learned these lessons when she was six years old and as Jean Piaget argues children at this age are ready to learn accurate and authentic information about the others and any personal prejudice can become an integral aspect of a child's attitudes and behavior. Likewise, twenty six years-old Scout, who has learned from Atticus that Blacks and Whites are equal as each other and the only difference between people is about their level of humanity, cannot tolerate that her father is acting in contrary to twenty years ago because color-blindness has become a part of her attitudes and behavior since her childhood.

She went to her father's chair to tidy up the papers he had left on the floor beside it. [...] and was doing so when a pamphlet the size of a business envelope caught her eye. On its cover was a drawing of an anthropophagous Negro; above the drawing was printed The Black Plague. Its author was somebody with several academic degrees after his name [6, p. $101]$.

When Scout returns back to Maycomb, she finds Atticus now as a racist who is on the board of directors in the "Maycomb County Citizens' Council" [6, p. 103]. Atticus was a pattern for Scout and believed that, "if there's one slogan in this world, [...] it is this: equal rights for all, special privileges for none" [6, p. 108] and now he was an unknown person for Scout. Atticus who had taught Scout that she should not call Negroes with the word of niggers, now himself inexorably used the word "nigger" [6, p. 150]. But, all these changes about her father do not influence on her since color-blindness has become a part of her character as the result of childhood training.

She opened the pamphlet, sat down in her father's chair, and began reading. When she had finished, she took the pamphlet by one of its corners, held it like she would hold a dead rat by the tail, and walked into the kitchen. She held the pamphlet in front of her aunt.

-"What is this thing?" she said.

Alexandra looked over her glasses at it. "Something of your father's".

Jean Louise stepped on the garbage can trigger and threw the pamphlet in [6, pp. 101-102].

Scout's childhood training keeps her away from Atticus's belief, though she has been worshiping her father since her childhood like an idol. Thus, it makes her angry when she finds that her righteous father has betrayed her and now is a racist person.

The one human being she had ever fully and wholeheartedly trusted had failed her; the only man she had ever known to whom she could point and say with expert knowledge, "He is a gentleman, in his heart he is a gentleman," had betrayed her, publicly, grossly, and shamelessly [6, p. 113].

When Scout goes to Maycomb's court to realize the truth about her father, she walked out to the "Colored balcony [...] and took her old place in the corner of the front row, where she and her brother had sat when they went to court to watch their father" [6, p. 105]. Sitting in the Colored balcony after twenty years shows that Scout does not forget her childhood training as a color-blind character. When she sits there she remembers the past and her father on the Tom's Trial that how he 
[T]ook his career in his hands, made good use of a careless indictment, took his stand before a jury, and accomplished what was never before or afterwards done in Maycomb County: he won an acquittal for a colored boy on a rape charge. The chief witness for the prosecution was a white girl. [...] After the verdict, he walked out of the courtroom in the middle of the day, walked home, and took a steaming bath. He never counted what it cost him; he never looked back. He never knew two pairs of eyes like his own were watching him from the balcony [6, p. 109].

Atticus could not see his children because his transparent eye does not perceive whether or not children and woman watch the trial. Atticus, however saw the truth and that was what he attempted to prove. In fact, Jem and Scout's eyes are like the eyes of To Kill a Mockingbird's Atticus as they do not see the colors of racism. They have learned from their childhood through Atticus' trains that all the people are equal and it's their duty to defend innocent Blacks when injustice is done towards them because they are humans, too, and discrimination, prejudice, and injustice towards them is wrong and unfair.

All these childhood trainings and what Scout remembers about his father in the past makes her furious about the present situation in Maycomb County that Atticus and Henry, her fiancée and childhood friend, are a part of it. But, what is discussable is the influence of Scout's childhood training as a color-blind person which does not change in her adulthood even when she sees her father, (her real champion and hero in her life, especially during her childhood), in contrary to his past beliefs.

She did not stand alone, but what stood behind her, the most potent moral force in her life, was the love of her father. She never questioned it, never thought about it, never even realized that before she made any decision of importance the reflex, "What would Atticus do?" passed through her unconscious; she never realized what made her dig in her feet and stand firm whenever she dis was her father; that whatever was decent and of good report in her character was put there by her father; she did not know that she worshiped him [6, pp. 117-178].

As it is obvious, childhood training is extremely useful that becomes a part of character as Jean Piaget also emphasizes. And nothing can change it even the cause of that training in the childhood. Scout in Go Set a Watchman goes against her father because her present father is now in contrary to his past father and her color-blindness trainings are now a part of her attitudes and behavior so that she cannot change them as she cannot change her personality. Scout has grown as an anti-racist person who does not believe in prejudice and discrimination so that she cannot tolerate them. She believes that Blacks are human and have the right to live like the others. When Alexandra says to Scout that there are a lot of truths in the book of The Black Plague, Scout gets too angry and says wryly,

Yes indeedy, [...] I especially liked the part where the Negroes, bless their hearts, couldn't help being inferior to the white race because their skulls are thicker and their brain-pans shallower-whatever that means - so we must all be very kind to them and not let them do anything to hurt themselves and keep them in their places. Good God, Aunty - [6, p. $102]$.

Therefore, as the result of her childhood training, Scout goes against her father because she observes him alien to her norms which she has learned in her childhood. Even she hates that Atticus calls her with her childhood name, (Scout). "His use of her childhood name crashed on her ears. Don't you ever call me that again. You who called me Scout are dead and in your grave" [6, p. 151]. Actually, Scout's childhood training is so deep so that she kills even her father in her heart and mind when she sees her different from the past.

Moreover, South area of America is more racist than its north. People in the South are more fanatic and therefore discrimination can be observed there more than the North areas. Further to her childhood training, Scout has lived in New York for several years after her graduation from 
College. Now Scout believes that, “you won't find better people than in New York", for "they go around loose up there, all kinds of folks" [6, p. 181].

Claudine hunched her shoulders. "I don't see how you live up there with them."

-"you aren't aware of them. You work with them, and you aren't aware of them unless you want to be. I don't know that a great big fat Negro man's been sitting beside me on a bus until I get up to live. You just don't notice it." [Scout says].

-"Well, I certainly noticed it. You must be blind or something."

Blind, that's what I am I never opened my eyes. I never thought to look into people's hearts, I looked only in their faces. [...] I need a watchman to lead me around and declare what he seeth every hour on the hour [6, p. 181].

And Scout knows that, "every man's watchman is his conscience" [6, p. 265]. Thus, she decides to obey her conscience and see the others with her unconquered eye, which is color-blind and does not see the differences of race colors.

Another situation in the story which reveals twenty six years-old Scout as a color-blind character is when she goes to the Negroes' settlement to visit Calpurnia and insure her that Atticus will help her grandson, Zeebo's boy, who had ran over old Mr. Healy crossing the road and had killed him dead [6, p. 148] regardless of the fact that Atticus won't do it.

She looked up, and on the pork of Calpurnia's little house stood Negroes in various states of public attire. [...] When they saw her, they stood straight and retreated from the edge of the porch, becoming as one. The men removed their hats and caps, the woman wearing he apron folded her hands beneath it [6, pp. 155-156].

It can be argued that after twenty years prejudice, injustice, and discrimination towards blacks they are still polite and respect Whites that manifests their good nature and humanity of Blacks. Near the end of the novel Scout in her quarrel with Atticus says,

I wonder what would happen if the South had a 'Be Kind to the Niggers Week'? if just for one week the South would show them some simple, impartial courtesy. I wonder what would happen. Do you think it'd give 'em airs or the beginnings of self-respect? Have you ever been snubbed, Atticus? Or you know how it feels? [6, p. 252]

Then she herself replies,

No, don't tell me they're children and don't feel it: I was a child and felt it, so grown children must feel, too. A real good snub, Atticus, makes you feel like you're too nasty to associate with people. How they're as good as they are now is a mystery to me, after a hundred years of systematic denial that they're human. I wonder what kind of miracle we could work with a week's decency [6, p. 252].

Therefore, based on Jean Piaget's theory of cognitive development, Scout has known Blacks as human and as equal as Whites. Thus, she does not any differences between these two races because of her childhood training. She has learned from her father when she was a six years old child that, "if you can learn a simple trick, Scout, you'll get along a lot better with all kinds of folks. You never really understand a person until you consider things from his point of view" [7, p. 33]. Likewise, Scout considers things from Black's point of view and never see any reason for discrimination, injustice, and prejudice towards them. Accordingly, it is only her childhood training which has built her a color-blind and anti-racist person who even fights against her father when she observes him in contrary to her norms.

\section{Fighting against racial discrimination as the result of childhood anti-racist training in Go Set a Watchman}

All the four categories of discrimination interpersonal, organizational, institutional, and cultural discrimination_are existed in Maycomb society from its past to its present. "Maycomb County Citizens' Council" is a kind of organizational and institutional discrimination which 
consider Blacks as second-class citizens, segregate them from Whites, and disenfranchise them so that based on the White's rules Blacks are all the time treated as savages and uncivilized creatures who do not deserve to live on welfare because they need Whites to have control over them otherwise there will be turbulence in a society. Accordingly, interpersonal and cultural discrimination happens because Whites know themselves and their culture superior to Blacks and does not accept them in their gatherings.

Interpersonal discrimination occurs when one person treats another unfairly because of the person's group membership [8]. Likewise, in Go Set a Watchman, people, especially the members of Maycomb County Citizen's Council, Blacks are treated unfairly because they are from a different group with differences like their skin color. Mr. Grady O'Hanlon, a speaker in Citizen's council, is an obvious example of interpersonal discrimination. In his speech he defines Black race as,

... a race as hammer-headed as... essential inferiority... kinky wooly heads... still in the trees... greasy smelly... marry your daughters... mongrelize the race... mongrelize... mongrelize... save the South... Black Monday... lower than cockroaches... God made the races... nobody knows why but He intended for 'em to stay apart... if He hadn't He'd've made us all one color... back to Africa... [6, p. 108].

Even he insults to the Black race and says, "These top-water nigger preachers... like apes... mouths like Number 2 cans... twist the Gospel... the court prefers to listen to Communists... take 'em all out and shoot 'em for treason..." [6, p. 108]. In fact, the way that he speaks about the Black race is nothing more except his fanatic and racist beliefs which comes from stereotypes in a culture. Stereotypes in Maycomb, which is an area in the South of America in the story, has passed from generation to generation so that it is near impossible to vanish them.

People in Maycomb "make no bones about saying they want to do away with the Negro race, and they will in four generations, $[\ldots]$, if they start with this one" $[6, p .176]$. In fact, they want to do away with the Negroes because they are afraid of mongrelizing their race. They believe in their superiority and do not want to share it with an inferior race. Therefore, preservation of segregation is Maycomb's main focus which its political men are dealing with. Indeed, Maycomb is afraid of its pure blood and their superiority and considers Blacks as a kind of threat, thus, "when a man's looking down the double barrel of a shotgun, he picks up the first weapon he can find to defend himself, be it a tone or a stick of stove-wood or a citizen's council" [6, p. 200].

Because of her growing up in an anti-racist family with a negro maid in the role of a mother and taking the anti-racist attitudes and learning to be against prejudice, discrimination, and injustice by her father's training in her six, Scout cannot adjust herself to the present situation.

$[\mathrm{N}]$ ever in my life until today did I hear the word "nigger" spoken by a member of my family. Never did I learn to think in terms of The Niggers. When I grew up, and I did grow up with black people, they were Calpurnia, Zeebo the garbage collector, Tom the yard man, and whatever else their names were. There were hundreds of Negroes surrounding me, they were hands in the fields, who copped the cotton, who worked the roads, who sawed the lumber to make our houses [6, p. 179].

Likewise, regardless of their positive role and doing manual labor, Blacks were always treated as nonhuman and inferior creatures born to serve Whites. They were treated unfairly for their different culture and color and were in a bad economic condition despite their hardworking. But, not their poverty and not their class and different color was a matter of importance for Scout to treat them differently from the white race.

They were poor, they were diseased and dirty, some were lazy and shiftless, but never in my life was I given the idea that I should despise one, should fear one, should be discourteous to one, or think that I could mistreat one and get away with it. They as a people did not enter my world, nor did I enter theirs: when I went hunting I did not trespass on a Negro's land, not because it was a Negro's, but because I was not supposed to trespass on anybody's land. I was taught never to take advantage of anybody who was less 
fortunate than myself, whether he be less fortunate in brains, wealth, or social position; it meant anybody, not just Negroes. I was given to understand that the reverse was to be despised. That is the way I was raised, by a black woman and a white man [6, p. 179].

Therefore, Scout fights against racial discrimination in her adulthood based on her childhood trainings and beliefs. She fights against Atticus because she believes that justice ought to be done towards all the members of a society and the Blacks are part of their society, too. She defends racial justice and says,

Atticus, I'm throwing it [the chair] at you and I'm gonna grind it in: you better go warn your younger friends that if they want to preserve Our Way of Life, it begins at home. It doesn't begin with the schools or the churches or any place but home. Tell 'em that, and use your blind, immoral, misguided, nigger-lovin' daughter as your example [6, p. 248].

Atticus was the person who has taught Scout about humanity, a notion that prevent people from prejudice, discrimination, and injustice. Learning the concept of humanity in her childhood, in fact, makes Scout to defend it and the human nature of Blacks even if that they are "backward, that they're illiterate, that they're dirty and comical and shiftless and no good, they're infants and they're stupid, some of them, but [...] they're human" [6, p. 251]. She defends Negroes and makes a quarrel with her father that,

You deny them hope. Any man in this world, Atticus, any man who has a head and arms and legs, was born with hope in his heart. You won't find that in the Constitution, I picked that up in church somewhere. They are simple people, most of them, but that doesn't make them subhuman $[6$, p. 251].

Finally, it can be concluded that Scout holds her attitudes and belief and fights against discrimination, prejudice, and injustice because these are her childhood trainings and are now a part of her character which nobody can vanish them even Atticus, the man who Scout was worshiping since her childhood and has taught her to be a color-blind person. And it can be obviously observed when Atticus at the end of the novel tells Scout that, "I certainly hoped a daughter of mine'd hold her ground for what she thinks is right — stand up to me first of all" [6, p. 77].

\section{Conclusion}

Racism, now as a global issue, has existed from the very beginning of human gatherings. Now, in the twenty first century it still exists in many countries especially racist countries like America. African Americans were always under the pressure of discrimination, prejudice, and racial injustice due to their different skin color and were treated as the inferior race throughout the history. They were segregated from the Whites' society behind a vast veil because they were known as the lowbrow and uncivilized people. Moreover, Blacks were always predetermined to be the subjects of any criminals, regardless of their innocence, which leads to their lynching in White courts. Therefore, racial discrimination in racist countries ignores the rights of Blacks as human beings and puts them in hard situation with many problems like injustice, prejudice, being excluded from their primarily rights as humans, living separated from the Whites in inappropriate places, education, and etc...

Therefore, many writers endeavored to eliminate racial discrimination and racism through their works. Harper Lee was a white novelist who defended Black's rights in her two novels To Kill a Mockingbird and Go Set a Watchman. In fact, Lee's two novels deals with the issue of racism and fight against any forms and types of discrimination, prejudice, and injustice. Lee in To Kill a Mockingbird depicts the life of Atticus and his two children, Scout and Jem, and tries to persuade people to coexist with each other in peace without paying attention to different race, culture, and class.

Lee in To Kill a Mockingbird portrays Atticus as a color-blind character who sees through his unconquered eye and "transparent eyeball" and therefore has insight rather than sight. Color- 
blindness, indeed, is the ability of seeing with an Emersonian "transparent eyeball" [9], which causes man to see right. It is an ideology which avoids people of colored skin to be seen differently and unequal to Whites. Therefore, in this regard, Harper Lee's masterpiece, To Kill a Mockingbird, can be a good case in point.

To Kill a Mockingbird (1960) is the story of a color-blind lawyer, Atticus, and his children who do not see any difference between Whites and Blacks, and the skin color, indeed, does not matter to them anywise. Atticus defends an innocent Negro and tries to obliterate discrimination, prejudice, racial injustice and inequality in Maycomb. In fact, he through his power of being colorblind has the ability to see clearly, which based on the Emersonian "transparent eyeball" is the result of his lack of physical sight that brings insight and wisdom. Likewise, he trains his children to be color-blind in the case of racism and also treat all the people as equal as each other. Atticus teaches his children to avoid discrimination, prejudice, and injustice because all the people with any race, class, or culture are humans and the only factor which causes them to be different is their level of humanity. Accordingly, one of the solution of racial issues, especially discrimination, is the power of being color-blind in the case of racism.

Moreover, To Kill a Mockingbird is narrated by the six years-old Scout that, based on Jean Piaget's theory of cognitive development, her trainings and learnings become a part of her personality in future. Jean Piaget in his theory of cognitive development classifies children of three to twelve year-olds in three different groups and states that children in any of these groups are ready to learn different facts or lies about race and therefore any prejudice or stereotypes which they learn in these ages can be an integral part of them in future.

Based on Piaget's theory, Scout and Jem respectively place in the second and third groups. Therefore, Scout, who is at the "socio-centric" stage of her development learns from Atticus, his father who is Scout's hero, that there is no difference between Whites and Blacks and the Negroes are humans, too. And this moral lesson builds a color-blind Scout who becomes a real anti-racist person in future. Accordingly, in Go Set a Watchman, which is Lee's sequel novel to the story of To Kill a Mockingbird, the influence of Scout's childhood training on shaping her anti-racist personality can be seen obviously. Scout fights against prejudice, injustice, and discrimination because these are in contrary to what she has learned in her childhood.

Nowadays, in the twenty- first century, the world is still a witness of racist attitudes and believes. Racist societies, especially their political men, cannot accept Blacks among themselves and as the result discrimination, injustice, and prejudice is not yet finished. Many African Americans are still killed innocently in racist countries, especially America, and their only sin is their color of skin. They are excluded from their rights and still are suffering from racial issues. On the other hand, Whites cannot change their attitudes towards Blacks because these attitudes are an integral part of their personality and happen unconsciously. Thus, training children, the future generation, as anti-racist and color-blind characters can be a good solution to eliminate social/racial/cultural discrimination.

\section{References}

[1] L. Derman-Sparks, C.T. Higa, B. Sparks, children, race and racism: how race awareness develops, Interracial Books for Children Bulletin. 11(3/4) (1980) 3-15.

[2] P.G. Devine, Stereotypes and prejudice: Their automatic and controlled components, Journal of Personality and Social Psychology. 56(1) (1989) 5-18.

[3] A. Beuf, Red children in white America, University of Philadelphia Press, 1977.

[4] J. Piaget, Rapport du directeur: cinquième réunion du Conseil. Genève, Bureau international d'éducation, 1934.

[5] J. Piaget, A.M. Weil, The development in children of the idea of the homeland and of relations with other countries, International Social Science Bulletin. 3(3) (1951) 561-578. 
[6] N.H. Lee, Go Set a Watchman, HarperCollins Publishers, New York, 2015.

[7] N.H. Lee, To Kill a Mockingbird, J.B. Lippincott Company, New York, 2010.

[8] N.V. Benokraitis, J.R. Feagin, Modern sexism: Blatant, subtle, and covert discrimination (2nd ed.), Englewood Cliffs, Prentice Hall, NJ, 1995.

[9] L. Champion, "When You Finally See Them": The Unconquered Eye in "To Kill a Mockingbird", The Southern Quarterly. 37(2) (1999) 237-253. 